\title{
Terapeutas ocupacionais na gestáo da atenção básica à saúde ${ }^{1}$
}

\author{
a,b Paula Giovana Furlan, ${ }^{\mathrm{b}}$ Marianna dos Santos Oliveira \\ ${ }^{a}$ Universidade Federal de São Carlos - UFSCar, São Carlos, SP, Brasil.

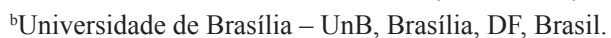

\begin{abstract}
Resumo: Introdução: A ampliação do campo de ação do terapeuta ocupacional em ambientes não hospitalares e asilares nas últimas décadas, com a territorialização das práticas de saúde no Sistema Único de Saúde, mostra a relação entre as possibilidades de atuação da profissão e as políticas públicas vigentes, incluindo funções de gestão e gerenciamento de serviços. Objetivos: Caracterizar a atuação do terapeuta ocupacional no âmbito da gestão da atenção básica à saúde do Distrito Federal e identificar os conhecimentos do núcleo profissional aplicados. Método: Pesquisa qualitativa, com o referencial da etnografia para produção e análise dos dados, com observação, diário de campo, entrevistas semiestruturadas e revisão bibliográfica. Os sujeitos foram dois terapeutas ocupacionais da Secretaria de Estado da Saúde do Distrito Federal, atuantes na gestão da atenção básica. Resultados: A ampliação do conceito de saúde resultou na incorporação de diferentes profissionais para compor a gestão de serviços e programas. A atuação do terapeuta ocupacional depende de seus conhecimentos do campo da gestão, do desenvolvimento de projetos coletivos e da integralidade do cuidado. Os terapeutas ocupacionais estudados estavam inseridos na gestão central e de programas assistenciais a populações específicas. Conclusão: Possibilitou a análise sobre a ampliação do espaço de atuação do terapeuta ocupacional, contribuindo para futuras discussões da formação profissional. Evidenciou-se que a formação do núcleo profissional oferece subsídios que favorecem uma prática ampliada na gestão, como habilidades para o trabalho em grupo, em equipe e em processos de exclusão social.
\end{abstract}

Palavras-chave: Gestão em Saúde, Atenção Primária à Saúde, Terapia Ocupacional, Integralidade em Saúde.

\section{Occupational therapists in primary care health management}

\begin{abstract}
Introduction: The expansion of the working field of occupational therapists in non-hospital environments and asylums in the last few decades, which came along with the territorial health practices in the National Health System, shows the relationship between the possibilities of professional performance and the existing public policies, including management functions and services. Objectives: To characterize the role of occupational therapists in the management of primary health care in the Distrito Federal and the professional knowledge used in this practice. Method: This was a qualitative research with production and analysis of data carried out through ethnography. Data were produced with aid of observations, field diary, semi-structured interviews and literature review. The study subjects were two occupational therapists from the State Secretariat of Health of the Distrito Federal who work in the management of primary health care. Results: The expansion of the concept of health has resulted in the incorporation of different professionals to compose the management of service and programs. The role of occupational therapists depends on their knowledge about management, collective projects and integral health care. Occupational therapists of this study work on central management and welfare programs to specific populations. Conclusion: The research made it possible to analyze the expansion of the working space of occupational therapists, contributing to future discussions on professional training. It was evident that the formation of the professional core provides subsidies for a larger management practice, such as skills for group and team work, and the work with socially excluded people.
\end{abstract}

Keywords: Health Management, Primary Health Care, Occupational Therapy, Integrality in Health.

Autor para correspondência: Paula Giovana Furlan, Departamento de Terapia Ocupacional, Universidade Federal de São Carlos, Rodovia Washington Luis, Km 235 SP 310, CEP 13565-905, São Carlos, SP, Brasil, e-mail: paulafurlan@unb.br

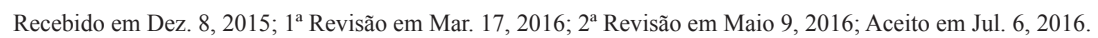




\section{Introdução}

O mecanismo de acesso ao serviço público de saúde como direito garantido a todos os cidadãos brasileiros foi instituído na década de 1990, perante a regulamentação da Lei Orgânica de Saúde (Lei no 8.080), constituindo assim o Sistema Único de Saúde (SUS) brasileiro (VIANA; DAL POZ, 1998). O SUS oferece como princípios e diretrizes a universalidade do acesso aos serviços de saúde, a equidade e a integralidade nas ações, a participação da comunidade e a descentralização dos serviços para os municípios e regióes. O cuidado integral da saúde, incluindo açóes de prevenção, promoção, tratamento e reabilitação, está organizado em eixos de atenção, buscando uma melhor programaçáo e o planejamento do sistema (NORONHA; LIMA; MACHADO, 2008).

A Política Nacional de Atenção Básica (PNAB) (BRASIL, 2006, 2012) descreve esse eixo de cuidado como o primeiro contato da populaçáo com o serviço de saúde, sendo regida pelos princípios da universalidade, acesso e da coordenaçáo do cuidado, da integralidade, vínculo, valorização do profissional e da participação popular. Essa é caracterizada por uma série de açôes em saúde, que abrangem as esferas individual e coletiva, a promoção da saúde, a prevenção de agravos, o diagnóstico, o tratamento, a reabilitação e a manutenção da saúde. A atualização recente da PNAB (BRASIL, 2012) trouxe elementos para o desenvolvimento da gestão compartilhada, das açóes intersetoriais visando à atenção integral, ampliação do acesso, fortalecimento do controle social e da participação da comunidade.

A inserção da Terapia Ocupacional no SUS tradicionalmente ocorreu a partir das consideradas alta e média complexidades, já que a atuação era voltada à atenção asilar, curativa, médico-hospitalar, devido aos modelos centralizadores existentes na época (PAIM; SILVA, 2010; VIANA; DAL POZ, 1998). Como consequência da organização do SUS, as demandas populacionais e o campo de açáo para a terapia ocupacional ampliaram, com novas inserçôes desde a década de 1990 em ambientes não hospitalares e asilares, incluindo a atenção básica (centros/ postos de saúde, unidades básicas etc.), ocorrendo a ampliação no campo de ação do terapeuta ocupacional, comprovando a intensa relação entre as possibilidades de atuação e as políticas públicas vigentes (OLIVER; BARROS; LOPES, 2005). Sabe-se que esse processo de inserçáo dos terapeutas ocupacionais na saúde pública não aconteceu de forma homogênea em todo país (MALFITANO;
LOPES, 2003; OLIVER; BARROS; LOPES, 2005), e que esse profissional adquiriu espaço e se estruturou de maneira significativa a partir de sua inserção no contexto da saúde pública.

Os questionamentos sobre os novos espaços de atuação e a real inserçáo do terapeuta ocupacional em diferentes espaços do SUS disparam discussōes sobre a prática e uma formação profissional condizente com as novas demandas e exigências (BRASIL, 2002).

As demandas populacionais e institucionais foram se transformando historicamente, e os terapeutas ocupacionais passaram a se confrontar com situaçóes que lhes exigem novos tipos de habilidades e competências para o exercício profissional, visando, por exemplo, compor equipes de gestáo (DE CARLO et al., 2009).

Sabe-se que no passado a equipe de gestáo era composta quase exclusivamente por médicos e a participaçáo dos terapeutas ocupacionais era pouco valorizada. As funçôes na gestão pública, na implantação e elaboração de políticas de saúde, na gerência de equipes e serviços eram atribuídas de maneira hierárquica entre as profissões. Entretanto, na realidade atual, o terapeuta ocupacional tem assumido papéis participativos e ativos nos equipamentos sociais em que se encontra inserido, portanto, conhecimentos e competências profissionais nas áreas de gestão e gerenciamento de serviços se tornaram cada vez mais necessários (SOUZA; AYRES; MARCONDES, 2012).

Nos dias de hoje, existe uma recente visão de gestão em saúde pública que se dá pela organização de serviços e programas em saúde seguindo uma nova racionalidade, essa antitaylorista (CAMPOS, 2007; BRASIL, 2009), contribuindo para a criação de espaços coletivos, beneficiando tanto aos profissionais quanto aos usuários, de forma a questionar organizaçóes centralizadas e hierárquicas, valorizar os saberes e circular os poderes institucionais.

Dessa forma, a gestão adquire um caráter mais participativo, ou seja, mais democrático nos serviços públicos de saúde. Desmistificando a organização do serviço de acordo com o saber categorizado de cada profissão e proporcionando a participação, cogestáo, corresponsabilizaçáo de todos que gerem (CAMPOS, 2007).

Embora ainda evidenciemos modelos de estruturas organizacionais (baseados no paradigma industrial) que sejam centrados na especialização, na produção em massa, em políticas impessoais, em padróes de procedimentos, atualmente vê-se ampliar no SUS o debate que busca um modelo de gestão participativa com a atuação de diversos profissionais, dentre 
eles o terapeuta ocupacional e os demais sujeitos participantes da instituição e dos equipamentos de saúde (DE CARLO et al., 2009; CAMPOS, 2007).

Considerando esse contexto, fez-se necessário evidenciar os fatores que circundam a participação do terapeuta ocupacional na gestáo, para que se construa uma nova oportunidade de ação e que desenvolva uma identidade nesse espaço. Este trabalho buscou caracterizar a atuação do terapeuta ocupacional no âmbito da gestão da atenção básica à saúde do Distrito Federal e identificar os conhecimentos do núcleo profissional utilizados para essa práxis.

\section{Método}

Caracterizou-se como uma pesquisa qualitativa, com o referencial da etnografia para produçáo e análise dos dados (LÜDKE; ANDRÉ, 1986; SPRADLEY, 1979).

Os sujeitos do estudo foram todos os profissionais terapeutas ocupacionais da Secretaria de Estado da Saúde do Distrito Federal, atuantes em cargos e funções de gestão na atenção básica em agosto de 2013 (quatro sujeitos). Os profissionais foram indicados pela Subsecretaria de Atençáo Básica do Distrito Federal e convidados a participarem do estudo, porém dois não aceitaram. Os participantes serão denominados por "Terapeuta Ocupacional 1" e "Terapeuta Ocupacional 2"; assinaram o Termo de Consentimento Livre e Esclarecido, atendendo às exigências éticas previamente estabelecidas.

A produção de dados foi realizada de agosto a novembro de 2013 através de: a) observação etnográfica dos Terapeutas Ocupacionais (quatro idas de uma das autoras do artigo a campo com cada terapeuta ocupacional), com registro em diário de campo (descritivos e reflexivos); b) entrevista semiestruturada composta por quatro questóes abertas, relacionadas à inserção na equipe de gestão, atribuiçôes, núcleo e formação profissional para o campo (gravação de áudio e transcrição); c) revisão bibliográfica de artigos científicos completos em português sobre a atuação profissional na área, no período de 2008 a 2013, em bases científicas (Scielo e BVS), com os descritores "terapia ocupacional" e "gestão em saúde".

A análise de dados etnográfica priorizou a descrição de significados do grupo determinado, buscando comprender através do ponto de vista e do contexto que os sujeitos interpretam suas açóes e pensamentos. A busca de evidências compóe o domínio misto e analítico, a partir do qual o fenômeno pode ser compreendido (LÜDKE; ANDRÉ, 1986; SPRADLEY, 1979).

\section{A Inserção e Atuação do Terapeuta Ocupacional na Gestão em Saúde da Atenção Básica no Distrito Federal}

A Terapia Ocupacional tem como desafio a sua inserção na Atenção Básica. Devido ao modelo organicista e biomédico existente no início da instituição do SUS, privilegiava-se que os terapeutas ocupacionais utilizassem procedimentos individuais realizados em serviços especializados. A participação desse profissional nas discussôes políticas repercutiu na constituição de novas possibilidades de intervenção na clínica da Atenção Básica e em outros espaços, como no campo da gestão em saúde. Nesse nível de atenção, o terapeuta ocupacional é responsável pelo planejamento, gerenciamento, coordenação e avaliação das açôes (ROCHA; PAIVA; OLIVEIRA, 2012).

Para tal, os terapeutas ocupacionais tenderam a buscar conhecimentos para atuar na clínica da Atenção Básica. Discute-se também a sua participação na equipe gestora (DE CARLO et al., 2009). O modelo de construção participativa das açóes em saúde faz com que ocorra a descentralizaçáo dos serviços e responsabilidades, deparando-se com a construçáa do novo modo de gerir (ARONA, 2009).

Não foram encontrados artigos que contemplassem a temática específica da gestáo e da terapia ocupacional na revisão bibliográfica com os descritores escolhidos. Nos três artigos encontrados, o terapeuta ocupacional é participante da mudança do modelo de gestáo em saúde do SUS, discutindo ações de formação em saúde e gestão democrática (Tabela 1).

Os artigos encontrados trazem como resultado comum a atuação do terapeuta ocupacional na gestão em saúde. Estimulam os profissionais a terem uma reflexáo crítica sobre o campo, para que tenham um olhar multidisciplinar e interdisciplinar, integrando seus saberes aos outros campos e que possam ser incluídos no novo contexto da gestáo da Atenção Básica.

A Atenção Básica no Brasil segue diversas diretrizes e normas, porém existem especificaçôes entre as várias regióes, culturas e ecossistema existentes no país. As açôes estão envoltas de um significado epistemológico e influenciado pela história e cultura de cada local (GOTTEMS et al., 2009).

A Atenção Básica no Distrito Federal surgiu a partir do plano nacional de saúde, em que a 
Tabela 1. Artigos revisão bibliográfica.

\begin{tabular}{|c|c|c|c|}
\hline Referência completa & $\begin{array}{c}\text { Banco de } \\
\text { Dados }\end{array}$ & Objetivo & Considerações do artigo \\
\hline $\begin{array}{l}\text { DE CARLO, M. M. R. P. et al. } \\
\text { Planejamento e gerenciamento } \\
\text { de serviços como conteúdos } \\
\text { da formação profissional em } \\
\text { terapia ocupacional: reflexões } \\
\text { com base na percepção } \\
\text { dos estudantes. Interface } \\
\text { - Comunicação, Saúde, } \\
\text { Educação, Botucatu, v. } 13 \text {, } \\
\text { n. } 29, \text { p. } 445-453,2009 \text {. }\end{array}$ & Scielo & $\begin{array}{l}\text { Analisar fatores que circundam } \\
\text { a formação de terapeutas } \\
\text { ocupacionais no que diz } \\
\text { respeito às ações de gestão e } \\
\text { planejamento em saúde. }\end{array}$ & $\begin{array}{l}\text { No âmbito da gestão, o } \\
\text { profissional deve estar } \\
\text { capacitado para comunicar-se, } \\
\text { planejar, executar, controlar } \\
\text { e avaliar serviços de saúde, } \\
\text { sejam eles hospitalares ou } \\
\text { não, bem como desenvolver } \\
\text { políticas, planos e programas } \\
\text { para o setor saúde. Entende-se } \\
\text { que estes são espaços de } \\
\text { produção e aplicação de } \\
\text { saberes destinados ao } \\
\text { desenvolvimento humano, } \\
\text { com vistas à melhoria } \\
\text { da qualidade de vida das } \\
\text { pessoas. }\end{array}$ \\
\hline
\end{tabular}

Com a proposta do matriciamento foi observado o interesse da participação

Implantar na Atenção Básica um projeto de intervenção na gestão local, buscando garantir às equipes das Unidades Básicas ARONA, E. C. Implantação do matriciamento nos serviços de saúde de Capivari. Saúde e Sociedade, São Paulo, v. 18, p. 26-36, 2009. Suplemento 1.
Scielo de Saúde maior apoio quanto à responsabilização do processo de assistência, garantindo a integralidade da atenção em todo sistema de saúde. de diferentes profissões na Atenção Básica, incluindo o terapeuta ocupacional.

O matriciamento

proporcionou a ampliação da resolubilidade das equipes, a definição do fluxo de encaminhamento, abertura de um canal de comunicação interprofissional e o estabelecimento de um espaço de cogestão.

Apesar dos avanços da Terapia Ocupacional, a profissão ainda encontra-se acanhada quantitativa e qualitativamente em relação a suas ações, atribuições e tecnologias. Com isso, tem-se a necessidade de aprofundar conhecimentos sobre o tema, para fortalecer e instrumentalizar a Terapia Ocupacional na Atenção Primária à Saúde.

Fornecer subsídios para mobilizar os terapeutas ocupacionais a reflexões e estudos que fundamentem e instrumentalizem a Terapia Ocupacional na Atenção Primária à Saúde (APS) quanto às suas atribuições, ações e tecnologias.

Primária à Saúde.

Constituição Federal de 1988 propunha a "saúde como direito de todos e dever do Estado", princípio regulamentado pelas Leis $n^{\circ} 8.080$ e no 8.142 25, publicadas em 1990. A proposta tinha a parceria do Ministério da Saúde, recebendo investimentos para a capacitação e qualificação dos trabalhadores de saúde. $\mathrm{O}$ modelo de organização da rede de Atenção Básica resultou em conflitos entre os profissionais e a gestáo da Secretaria de Saúde, tendo como pauta de discussão o processo de trabalho. Como resultado desses debates surgiu a Estratégia de Saúde da Família, que foi o marco das mudanças que ocorreram nesse período (GOTTEMS et al., 2009).

A gestão em saúde do Distrito Federal vem sofrendo mudanças no que diz respeito à constituição das equipes de gestão da Atenção Básica. As pautas de discussōes atuais referem-se à reorganização e ao fortalecimento desse nível de atenção, pois se sabe que essa é uma das principais propostas das políticas públicas atuais. 
Além da participação dos servidores nos processos de decisão, a gestão se abriu aos cidadãos atendidos nas unidades, sendo possível ampliar espaços de escuta e trocas entre trabalhadores e usuários.

Por ser Atenção Básica e por ter todas essas diretrizes, a gente trabalha para que se tenha um contexto de gestäo diferenciado, menos hierarquizado, mais horizontalizado, mais participativo com os atores. Podemos ver a mudança na gestão do Distrito Federal, podemos achar esse contexto de gestão, hoje em dia, em diversas regionais (Terapeuta Ocupacional 2).

A descentralização e a expansão dos serviços no SUS estáo resultando em uma composição da equipe de gestão que não atribui a função de gestor a um profissional apenas por saber clínico e a sua categoria profissional (BRASIL, 2009). A gestão participativa, sendo o novo modelo priorizado pelas diretrizes do SUS, visa à construção de espaços coletivos sob uma perspectiva antitaylorista. Essa forma de gerir favorece a inserção de diversos profissionais na equipe e até mesmo a participação do usuário (BRASIL, 2009; CAMPOS, 2007).

A Atenção Básica tem assumido um papel ativo na reorganização do modelo de gestão e atenção em saúde, para que essa nova ação alcance a atençáo integral, com base nas necessidades sociais e a população. Deve buscar a resolutividade e o fortalecimento da autonomia das pessoas (profissionais e usuários) no cuidado à saúde e também estabelecendo articulação com as demais redes de serviços (ROCHA; PAIVA; OLIVEIRA, 2012).

O modelo de gestáo hierarquizada e vertical dificulta e fragmenta o processo de trabalho e a integralidade do cuidado. Para que ocorra um trabalho integrado que contribua para aumentar o impacto das açóes, é importante não somente facilitar a comunicação entre as várias unidades de saúde, setores e níveis gerenciais, mas adotar um sistema que produza um compartilhamento simultâneo de responsabilidades pelas açôes sistemáticas com definição de papéis (BRASIL, 2009).

O terapeuta ocupacional pode contribuir para o exercício dessa função a partir do modelo de gestão participativa, em que é essencial a valorização dos diversos saberes profissionais existentes para que seja viável a formação das equipes de gerência. Por meio de discussōes entre todos os profissionais, é possível acordar a corresponsabilização no cuidado, cogestão e coordenação dos casos e a definição das tecnologias a serem empregadas (ROCHA; PAIVA; OLIVEIRA, 2012).
Na perspectiva dos profissionais participantes desta pesquisa, a gerência deve ser entendida como atribuição dos dirigentes, trabalhadores e usuários, para que assim ocorra a construção de um projeto que atenda às necessidades reais da população e que esteja voltado para a integralidade nas açôes em saúde.

Como estratégia dessa gestáo democrática, surge a formação de espaços coletivos. A busca por dispositivos capazes de criar espaços permanentes de discussão e reflexão sobre o trabalho, a gestão e todas as açóes de saúde, facilita o manejo dos conflitos e a identificação de estratégias visando solucionar questôes referentes aos processos de saúde, já que as decisóes são tomadas no coletivo, composto tanto por profissionais quanto por usuários do serviço (PIMENTA, 2012).

Porém, ainda existem divergências no modo de gerir, pois sabe-se que a gestáo é de natureza política, o que pressupóe a existência de atores políticos em jogos de poder e interesse (PIMENTA, 2012). Isso implica diretamente nos resultados esperados para a atenção continuada à saúde, como evidenciado na fala da Terapeuta Ocupacional 2:

[...] a gestão anterior sai e tudo muda. Não existe um padräo para gerir, não existem manuais, não existe um parâmetro que possamos nos orientar, nada que seja oficializado e acaba que cada um faz a seu modo. Existem diversos trabalhos sendo feitos na rede, então é importante que a próxima gestão os mantenham em ação. A gestão ainda é centrada em quem está no comando, centrada em pessoas, então muitas vezes isso prejudica na ação dos projetos.

Weirich et al. (2009) afirmam que é fundamental reconhecermos que o Estado brasileiro está defasado, no que se refere ao acesso a instrumentos gerenciais. Para que ocorra um desenvolvimento favorável ao processo gerencial, os gestores devem estar em sintonia com as atuais diretrizes operacionais para a atuação da função. A Terapeuta Ocupacional 2 aponta um conflito em relação à gestáo associada a projetos políticos partidários ou de um grupo do governo, o que dificulta a continuidade de estratégias que, para ter resultados eficazes, muitas vezes necessitaria mais que o tempo do mandato do cargo eleitoral.

Evidenciamos durante a reunião de gestores realizada em uma Clínica da Família apoiada pela Terapeuta Ocupacional 2, que os gerentes presentes náo sabiam ao certo sobre a existência dos documentos que norteiam as açóes da gerência. Expuseram que o processo de trabalho dos coordenadores de projetos e gerentes dos centros de saúde é visto com dificuldade, por não se ter clareza sobre suas funções, 
diretrizes, e isso resulta na maneira de legitimar esse papel. Os gestores colocam em debate que, se tivessem acesso a essas diretrizes, consequentemente ocorreria o aumento da eficiência no campo da prestação e continuidade de serviços. Então, muitas vezes, os documentos, mesmo existentes, não são disponibilizados pelos gestores locais, por razóes não identificadas.

Em discussão, a Terapeuta Ocupacional 2 esclareceu sobre a existência dos documentos norteadores. Porém, ressaltou que a Secretaria de Saúde não limita as ações desses profissionais, já que estes devem ter autonomia para identificar demandas e formular projetos para a região e população que buscam alcançar.

Os gestores devem ter claro seus objetivos, isso facilita o entendimento da equipe e só assim é possivel otimizar as açóes na comunidade (Terapeuta Ocupacional 2).

Segundo Merhy (1997), o gestor de saúde é um agente em situação de governo; isso resulta em ser um ator do coletivo, ou seja, não significa que ele tenha que tomar decisóes por si só, e sim ser o interlocutor dos demais. Um projeto de açóes em saúde, mesmo que no primeiro instante seja representado por uma única pessoa, deve ter o aval dos demais sujeitos envolvidos, já que o direcionamento das açôes serão dadas por outros atores e em um cenário peculiar, com suas dificuldades e conflitos que não aparecem na formulação inicial do projeto.

Soubemos durante a pesquisa que, para tornar-se o gerente de algum serviço de saúde do SUS no DF, não existe concurso público. $\mathrm{O}$ cargo de gerente é caracterizado como um cargo de confiança, já que os profissionais que irão ocupar esse lugar são escolhidos por possuírem características e interesses para atuar na função. Esses profissionais são indicados em função de sua representatividade no contexto onde atuam, fator esse também é relatado no estudo de Weirich et al. (2009).

Por meio das entrevistas, identificamos que a inserção dessas terapeutas ocupacionais no cenário na gestáo da Atenção Básica no Distrito Federal ocorreu, coincidentemente, por um convite da gestão anterior. O reconhecimento profissional foi o ponto primordial para que tivessem a oportunidade de ocupar esses cargos.

Precisavam de uma coordenadora para o programa saúde do adolescente, a gestão me chamou e eu aceitei o cargo. Já tinha trabalhado com adolescentes e gosto muito dessa área (Terapeuta Ocupacional 1). Eu trabalhava na coordenação do NASF e mudou o subsecretário de saúde e recebi um convite para eu assumir a Gerencia de Gestão. Eu já a conhecia e dentro da coordenação do NASF eu trabalhava em parceria com essa gerência (Terapeuta Ocupacional 2).

Apesar de toda essa discussão sobre o novo modelo de gerir em saúde, durante uma reunião de gestores que coordenam projetos em várias regionais do Distrito Federal na Atenção Básica, observamos que a medicina possui ainda uma maior relevância na atuaçáo em gestáo sobre as demais profissóes no SUS. Desse modo, ocorre a valorizaçáo do seu desempenho profissional, de sua contribuição na implantação e na manutenção da política de saúde e, consequentemente, na gestão de sistema de saúde. Sobretudo os enfermeiros também possuem uma forte representação na composição das equipes de gestão.

As competências e habilidades específicas para a área de administração e processo gerencial são mais comuns em determinadas profissóes, tais como medicina e enfermagem. Nessas profissões é comum que a formação gerencial seja desenvolvida durante a graduação e que haja uma relação de hierarquia perante o perfil profissional (DE CARLO et al., 2009).

No estudo realizado por Pimenta (2012), em que relata a experiência da construçáo de colegiados de gestão na Atenção Básica no município de Amparo, foi evidenciado que, naquele contexto, para o profissional fazer parte da equipe de gestão, ele passa por uma seleção que busca um trabalhador com longo tempo de experiência no SUS, que se destaque em múltiplas açóes realizadas no serviço e que tanto sua formaçáo quanto profissão tenham relação direta com o saber requerido na área específica dessa função.

É inegável que todo esse processo de identificação com a função de gerir um serviço norteia a reordenação da gestão em saúde da Atenção Básica no DF. Já que nos dias de hoje o gestor deve ter entendimento global das ações e uma apropriação clínica, e não necessariamente um conhecimento específico de tal categoria. É necessário frisar que gestóes mais participativas tendem a propiciar a inserção de novos profissionais na gestão, porém o que vemos ainda são modelos prioritariamente arraigados em determinadas profissôes, afirmando o modelo biologicista (medicalizante e prescritivo), o que reflete diretamente na escolha do profissional apto a integrar uma equipe de gestão.

Observamos o interesse dos profissionais médicos, enfermeiros e administradores ao tema desta pesquisa, 
que já na apresentação levantaram questôes como: "Por que Vocês Escolheram esse Tema? Mas Apenas Terapeutas Ocupacionais da Atenção Básica? Quantos São? Aonde Atuam?". Ficaram surpresos ao saber que existiam outros terapeutas ocupacionais na gestão da atençáo básica, perguntaram se eles estariam nos Centros de Atenção Psicossocial (CAPS). Quando relatamos que as profissionais não geriam serviços de saúde mental, demonstraram reação de espanto.

A categorização, ou seja, a rotulação do campo de atuação dos terapeutas ocupacionais, é evidenciada com frequência nos discursos de diferentes profissionais de saúde, que ao menos sabem o significado da Terapia Ocupacional (DE CARLO et al., 2009).

Constatamos que o trabalho do terapeuta ocupacional na gestấo da Atenção Básica do Distrito Federal não difere de outros gestores por sua formação acadêmica. O gestor necessita planejar açôes transdisciplinares, dialogar entre as diferentes áreas, buscar novas práticas do pensar e do agir, dentre outros. Nesse sentido, o terapeuta ocupacional é um profissional capaz de gerenciar de forma eficiente a complexidade das atividades nas instituiçôes de saúde, adquirindo autonomia no processo de aquisição e disseminação do conhecimento para ser um agente multiplicador apto a resolver com os demais profissionais e usuários questôes internas e externas (ARONA, 2009).

Acredito que ainda existe um pouco de preconceito contra quem não é médico para assumir cargos de gestão, mas isso vem mudando. O T.O. precisa mostrar a que veio, e se provar que entende do assunto não encontrará resistências! Lógico que tem um monte de gente com que eu trabalho que não sabe o que é T.O., mas sabem que o T.O. pode ser um bom gestor (Terapeuta Ocupacional 1).

Em síntese, podemos dizer que a atuação do terapeuta ocupacional como gestor na atenção básica depende, primeiramente, do conhecimento sobre gestão em saúde, dos caminhos do seu próprio processo de atuação profissional, da facilidade ao desenvolver projetos coletivos, como também de criar atividades capazes de integrar o cuidado em saúde.

Outro ponto que gostaríamos de destacar é que a organização da atenção básica favorece para que $\mathrm{o}$ terapeuta ocupacional faça parte da gestão. A nova perspectiva de saúde, voltada para a promoçáo e prevenção, sem o olhar direcionado apenas para a doença, faz com que seja necessária a atenção universal, com uma abordagem integral e horizontal nos sistemas de saúde, garantindo cuidados norteados pela qualidade, com ênfase na intersetorialidade, participação social e responsabilização dos governos.
Esse modo de compreender a Atenção Básica passou a ser o principal motivo para atuação do terapeuta ocupacional na função de gestor, a ampliação do conceito de saúde resultou na ampliação das formas de abordar o cuidado, e com isso o aceite de diferentes profissionais para compor a gestáo objetivando práticas eficientes (BRASIL, 2009).

\section{O Cotidiano e Atribuições do Terapeuta Ocupacional na Práxis da Gestão em Saúde da Atenção Básica do DF}

A Terapeuta Ocupacional 1 exerce a função de Coordenação do Programa de Atenção Integral à Saúde do Adolescente de uma Regiáo Administrativa do Distrito Federal. Participam dessa equipe médicos, enfermeiros, psicólogos e a terapeuta ocupacional. O Programa tem como objetivo garantir atenção integral às pessoas jovens compreendendo os aspectos biológicos, psicológicos e sociais da saúde do sujeito inserido em contexto social, cultural e familiar, singulares e em um território específico (BRASIL, 2010).

Ser coordenadora é um grande desafio, já que não se recebe gratificação pela função e é um cargo de grande responsabilidade (Terapeuta Ocupacional 1).

Nesse contexto, a Terapeuta Ocupacional 1 tem como atribuições planejar em conjunto com os Centros de Saúde da região as atividades previstas pelo Programa (grupos, oficinas, açóes nas escolas), supervisionar e avaliar as atividades relacionadas aos adolescentes nos Serviços de Saúde e estabelecer articulaçóes e parcerias com a rede intersetorial.

Outra atribuição desse cargo é promover cursos de educação continuada teóricos e práticos, bem como treinamento em serviços para os profissionais. $\mathrm{Na}$ coordenação faz matriciamento e capacitação das equipes de saúde in loco, ou seja, ela vai até o Centro de Saúde. Essa demanda surgiu dos próprios profissionais de saúde, que relatavam a carência de conhecimentos específicos sobre a saúde do adolescente.

Pudemos presenciar a atuação da Terapeuta Ocupacional 1 numa escola. Lá se encontravam a coordenação escolar e o enfermeiro que estava em processo de capacitação para açóes do Programa nessa escola. Com as turmas de $8^{\circ}$ e $9^{\circ}$ ano, foi realizada uma palestra sobre o uso de drogas e uma dinâmica grupal. Inicialmente, a Terapeuta Ocupacional 1 se responsabilizou pela palestra e a dinâmica, mas 
sempre pedindo que o enfermeiro contribuísse com seus conhecimentos técnicos acerca da temática.

Vou junto com os profissionais durante 5 encontros na escola que irá ficar sob sua responsabilidade, para que depois ele se sinta empoderado a ir sozinho ou com outro profissional de saúde (Terapeuta Ocupacional 1).

Após esse encontro, marcamos para ir à Secretaria de Saúde, na reunião dos Coordenadores do Programa das diferentes Regionais Administrativas. A cultura médica imperava nesse espaço, com discussóes clínicas nas quais os médicos faziam os encaminhamentos apontando o que cada profissional deveria fazer. Questionada sobre a situação, a Terapeuta Ocupacional 1 respondeu: "A cultura médica éainda muito presente, são profissionais antigos que ainda não evidenciaram a mudança no SUS”.

Nessa situação, o espaço coletivo estava enfraquecido, era visível o desconforto dos outros trabalhadores às pontuaçôes e determinaçóes das ações apenas pelos médicos; por outro lado, também não houve indagações de outros profissionais, ou seja, não se disparou a discussão nesse espaço, facilitando a construção de análises, tomadas de decisóes e avaliaçôes construídas pelo coletivo.

Pode-se observar que a Terapeuta Ocupacional 1 desenvolve açôes de organização e planejamento do Programa específico e que também desenvolve a clínica/apoio matricial, a fim de capacitaçáo dos demais profissionais na prática com a população adolescente. Ela organiza a proposta em conjunto com os profissionais e executa junto a eles a ação, sendo responsável pelo atendimento à população em conjunto com os demais profissionais, até que a ação esteja estruturada nos serviços e possa ser conduzida somente pelos profissionais dos locais.

Em nível central, a Terapeuta Ocupacional 2 tem como cargo a Gerência de Gestão da Subsecretaria de Atenção Primária em Saúde do Distrito Federal. A equipe dessa gerência é constituída por médicos, enfermeiros, assistentes sociais, administradores, terapeutas ocupacionais e odontólogos. Essa gerência é responsável por toda a Atenção Básica de saúde para implantação, renovação e formação de equipes, construção, reforma e ampliação de unidades de saúde, além de proporcionar cursos de educação permanente a todos profissionais.

Dentre todas essas atribuiçóes, a Terapeuta Ocupacional 2 faz a articulação entre as gerências existentes na Atenção Básica para análise de recursos humanos, alocaçáo de profissionais, levantamento de demandas dos gerentes de NASF, Equipe de Saúde da Família (EFS), e Centros de Saúde. “Atuo juntamente com o núcleo de normatização, que trabalha com as normas, diretrizes e portarias que regulam, regulamentam e direcionam todos os profissionais da atenção básica" (Terapeuta Ocupacional 2).

$\mathrm{Na}$ observação, verificamos a comunicação entre essas gerências. As ações no momento estavam voltadas à alocaçáo de novos médicos do "Programa Mais Médicos" do Governo Federal, tais como mediação de conflitos existentes nos locais onde estes estão inseridos e acolhimento dos novos profissionais. Porém, essas demandas não eram resolvidas de maneira isolada, existia a comunicação não apenas com as gerências internas, mas as externas (Centros de Saúde, NASF, dentre outros) também eram consultadas e participantes das informaçôes.

Uma das grandes atribuiçôes é ser um grande articulador entre as gerências que estão aqui da SES e as que estão nas regionais e até mesmo as secretarias que não são da saúde, mas são do governo (Terapeuta Ocupacional 2).

O trabalho interdisciplinar é um desafio no SUS, principalmente entre gestôes distintas. Campos e Domitti (2007, p. 405) afirmam que

[...] os profissionais habituaram-se a valorizar a autonomia profissional, julgando-a conforme o direito que teriam de deliberar sobre casos de modo isolado e definitivo.

A participação da Terapeuta Ocupacional 2 nos colegiados de gestão das unidades básicas é um reflexo da nova gestão priorizada pelo SUS. Com esse movimento de aproximação dos serviços e profissionais, as demandas são debatidas e levadas diretamente para a gestão de nível estadual. Por existir esse diálogo direto, surgem encaminhamentos mais específicos. A gestão não deve ser isolada nos serviços, a informação deve transitar nos diversos setores para a identificação dos problemas e, assim seja possível, solucioná-los. Diante disso, todos os sujeitos envolvidos serão considerados protagonistas e corresponsáveis na atenção integral à saúde. A participação da terapeuta ocupacional gestora nas unidades de saúde não é vista de forma desfavorável, no sentido de cobrança ou fiscalização.

Horizontalizar o poder, ampliar a inclusão de sujeitos na gestão e na clínica, construir corresponsabilização, náo são atos do acaso, mas construídos segundo dispositivos e arranjos para tal fim (PASCHE, 2010, p. 66).

Para que se tenha espaço nesse contexto de atuação, o terapeuta ocupacional na gestão em saúde da Atenção Básica deve consolidar conhecimentos e se reconhecer 
na função. Seja pelo desenvolvimento do saber mais específico para a ação ou pela própria vivência e competência profissional (DE CARLO et al., 2009).

A construção do saber e sua esquematização na prática dar-se-ão mediante a formação de um núcleo, esse seria a somatória de conhecimentos e de certa forma a demarcação de um campo. Segundo Campos (2007), o núcleo demarcaria a identidade de uma área de saber e da prática profissional, e o campo é o espaço de limites onde cada profissão buscaria em outra o apoio para cumprir suas tarefas teóricas e práticas. Sendo assim, o núcleo indicaria uma aglutinação, uma determinada concentração de saberes e de práticas, sem contudo indicar um rompimento radical com a dinâmica do campo.

Evidenciamos que, para adquirir conhecimentos e habilidades para a práxis na gestão, estes profissionais buscaram cursos, capacitaçôes ou especializaçóes que possibilitassem o embasamento teórico-metodológico necessário. Porém, relataram que o conhecimento obtido anteriormente na prática clínica também é importante para a construção do "terapeuta ocupacional gestor", e que foi nesse período que o interesse pela área da gestão foi constituído.

É imprescindivel que o terapeuta ocupacional tenha uma formação em gestão, seja um curso, mestrado ou até mesmo participar de projetos. Mas acima de tudo só iremos aprender mesmo na vivência (Terapeuta Ocupacional 2).

O processo de incorporação dessa função muitas vezes ocorre de maneira experimental, ou seja, as destrezas e técnicas para gerir um serviço surgem durante a execuçáo das diferentes atividades que envolvem esse cargo (DE CARLO et al., 2009). Sobre a maneira como o profissional se insere na gestão:

O primordial para a inserção do T.O. na gestão éo seu dominio sobre o assunto, interesse e perfil pessoal. Habilidade para gerir pode ser conquistada com estudo e experiência (Terapeuta Ocupacional 1).

O modelos de gestáo mais democráticos fazem com que o profissional busque constantemente por conhecimentos que abranjam não apenas as questôes como planejar, administrar e coordenar projetos. É necessário que ele construa estratégias junto às equipes como o apoio matricial e institucional e que seja possível a capacitação de outros profissionais envolvidos.

Verificamos que o terapeuta ocupacional demonstra ter habilidades como a flexibilidade e a criatividade, a relação interpessoal, a escuta atenta, que podem favorecer um processo de gestáo.
Pela formação que eu tive e pela experiência profissional que está além da academia, eu tento trazer um pouco daquilo que é da clínica da T.O. para a minha condição de gestora. Eu tento trabalhar, por exemplo, em equipe, a questão da escuta, de manter uma certa horizontalidade, de manter o espaço de discussão, isso vem da minha formação, é uma herança que eu trago da minha formação como terapeuta ocupacional (Terapeuta Ocupacional 2).

Diante das reflexóes sobre a atuação do terapeuta ocupacional na gestão em saúde, é possível perceber a necessidade da formação nessa área. Porém, a atualização técnico-científica é apenas um dos aspectos da qualificação das práticas e não seu foco central (DE CARLO et al., 2009).

Os profissionais da TO não têm uma formação para ser gestor, e o terapeuta ocupacional tem uma dificuldade no que se refere à administração, recursos humanos e isso muitas vezes dificulta e atrasa o nosso trabalho, não saimos preparados da graduação para sermos gestores (Terapeuta Ocupacional 2).

Dessa forma, acreditamos que formaçáo para a ação de gestão deveria englobar aspectos de produção de subjetividade, produção de habilidades técnicas e de pensamento e o conhecimento do SUS e políticas públicas. A formação para a área deveria ter como objetivo a transformaçáo das práticas profissionais e da própria organização do serviço, e estruturar-se a partir da problematização do processo de trabalho e sua capacidade de dar acolhimento e cuidado às várias dimensões e necessidades de saúde das pessoas, dos coletivos e das populaçóes.

\section{Conclusão}

O estudo possibilitou constatar e refletir sobre a ampliaçáo do espaço de atuação do terapeuta ocupacional para o campo da gestão, além da prática estritamente clínica, contribuindo para futuras discussões de formação profissional e das habilidades necessárias para a profissão no contexto atual da saúde pública brasileira.

Pode-se dizer que, pela tradição da gestão em saúde ser exercida pelos profissionais médicos e enfermeiros, uma gestáo participativa e democrática poderia inserir mais os terapeutas ocupacionais nessa função. A partir de uma prática clínica desenvolvida inseparável da prática da gestão e da apropriação de seus instrumentos e diretrizes, os terapeutas ocupacionais tornariam-se visíveis nesse cenário. 
Ao mesmo tempo, pode-se dizer que a formação profissional do "núcleo" oferece subsídios para uma prática ampliada, como habilidades para o trabalho em grupo, em equipe e em processos de exclusão social, pois são conceitos centrais na profissão.

\section{Referências}

ARONA, E. C. Implantaçáo do matriciamento nos serviços de saúde de Capivari. Saúde e Sociedade, São Paulo, v. 18, p. 26-36, 2009. Suplemento 1.

BRASIL. Ministério da Saúde. Conselho Nacional de Educação. Diretrizes Curriculares Nacionais do Curso de Graduação em Terapia Ocupacional. Diário Oficial [da] República Federativa do Brasil, Brasília, DF, 19 fev. 2002.

BRASIL. Ministério da Saúde. Secretaria de Atenção à Saúde. Departamento de Atenção Básica. Política Nacional de atenção básica. Brasília: Ministério da Saúde, 2006.

BRASIL. Ministério da Saúde. Secretaria de Atenção à Saúde. Politica Nacional de Humanização da atenção e Gestão do SUS. Redes de produção de Saúde. Brasília: Ministério da Saúde, 2009.

BRASIL. Ministério da Saúde. Secretaria de Atençáo à Saúde. Departamento de Açốes Programáticas Estratégicas. Diretrizes nacionais para a atenção integral à saúde de adolescentes e jovens na promoção, proteção e recuperação. Brasília: Ministério da Saúde, 2010.

BRASIL. Ministério da Saúde. Secretaria de Atenção à Saúde. Departamento de Atenção Básica. Política Nacional de Atenção Básica. Brasília: Ministério da Saúde, 2012.

CAMPOS, G. W. S. Um método para análise e co-gestão de coletivos: a constituição do sujeito, a produção de valor de uso e a democracia em instituições: método da roda. São Paulo: Hucitec, 2007.

CAMPOS, G. W. S.; DOMITTI, A. C. Apoio matricial e equipe de referência: uma metodologia para gestáo do trabalho interdisciplinar em saúde. Cadernos de Saúde Pública, Rio de Janeiro, v. 23, n. 2, p. 399-407, 2007.

DE CARLO, M. M. R. P. et al. Planejamento e gerenciamento de serviços como conteúdos da formação profissional em Terapia Ocupacional: reflexôes com base na percepção dos estudantes. Interface - Comunicação, Saúde, Educação, Botucatu, v. 13, n. 29, p. 445-453, 2009.

GOTTEMS, L. B. D. et al. Trajetória da política de atenção básica à saúde no Distrito Federal, Brasil (1960 a 2007): análise a partir do marco teórico do neo-institucionalismo histórico. Caderno Saúde Pública, São Paulo, v. 25, n. 6, p. 1409-1419, 2009.

LÜDKE, M.; ANDRÉ, M. E. D. A. Pesquisa em educação: abordagens qualitativas. São Paulo: EPU, 1986.

MALFITANO, A. P. S.; LOPES, R. E. Programa de Saúde da Família e agentes comunitários: demandas para além da saúde básica. Revista de Terapia Ocupacional da
Universidade de São Paulo, São Paulo, v. 14, n. 3, p. 110117, 2003.

MERHY, E. E. Em busca do tempo perdido: a micropolítica do trabalho vivo em saúde. In: MERHY, E. E.; ONOCKO, R. (Org.). Agir em saúde: um desafio para o público. São Paulo: Hucitec, 1997. p. 71-112.

NORONHA, J. C.; LIMA, L. D.; MACHADO, C. V. O Sistema Único de Saúde-SUS. In: GIOVANELLA, L. et al. (Org.). Politicas de Saúde no Brasil. Rio de Janeiro: Fiocruz, 2008. p. 435-472.

OLIVER, F. C.; BARROS, D. D.; LOPES, R. E. Estudo sobre a incorporação da terapia ocupacional no contexto das ações de saúde mental e saúde da pessoa com deficiência no Município de São Paulo entre 1989 e 1993. Revista de Terapia Ocupacional da Universidade de São Paulo, São Paulo, v. 16, n. 1, p. 31-39, 2005.

PAIM, J. S.; SILVA, L. M. V. Universalidade, integralidade, equidade e SUS. BIS, Boletim do Instituto da Saúde, São Paulo, v. 12, n. 2, p.109-114, 2010.

PASCHE, D. F. Humanizar a formação para humanizar o SUS. In: BRASIL. Ministério da Saúde. Politica Nacional de Humanização. Formação e intervenção. Brasília: Ministério da Saúde, 2010. p. 63-71. (Cadernos Humaniza SUS).

PIMENTA, A. L. A construção de colegiados de gestão: a experiência de gestão da Secretaria Municipal de Saúde analisada por um ator político implicado. Saúde Sociedade, São Paulo, v. 21, p. 29-45, 2012. Suplemento 1.

ROCHA, E. F.; PAIVA, L. F. A.; OLIVEIRA, R. H. Terapia Ocupacional na Atençăo Primária à Saúde: atribuiçôes, açôes e tecnologias. Cadernos de Terapia Ocupacional da UFSCar, São Carlos, v. 20, n. 3, p. 351-361, 2012.

SOUZA, C. C. B. X.; AYRES, S. P.; MARCONDES,

E. M. M. Metodologia de apoio matricial: interfaces entre a Terapia Ocupacional e a ferramenta de organização dos serviços de saúde. Cadernos de Terapia Ocupacional da UFSCar, São Carlos, v. 20, n. 3, p. 363-368, 2012.

SPRADLEY, J. The ethnographic interview. Worth: Hancourt Brace Jovanovich College, 1979.

VIANA, A. L. D.; DAL POZ, M. R. A reforma do sistema de saúde no Brasil e o Programa de Saúde da Família. Physis: Revista de Saúde Coletiva, Rio de Janeiro, v. 8, n. 2, p. 11-48, 1998.

WEIRICH, C. F. et al. O trabalho gerencial do enfermeiro na Rede Básica de Saúde. Texto \& Contexto - Enfermagem, Florianópolis, v. 18, n. 2, p. 249-257, 2009. 


\section{Contribuição dos Autores}

As autoras trabalharam em conjunto na concepção do artigo bem como aprovaram a versão final do texto.

\section{Notas}

${ }^{1} \mathrm{O}$ artigo é parte de pesquisa "Cartografia do Apoio Institucional e Matricial no SUS do Distrito Federal: áreas prioritárias da atenção e gestão em saúde e a formação de apoiadores na atenção primária em saúde" (parceria entre UnB/ FIOCRUZ/ SAPS-SES-DF), de coordenação da Profa. Dra. Paula G. Furlan, com aprovação dos Comitês de Ética em Pesquisa: UnB-FS 191.003 e FEPECS 453.476. 